\title{
COVID-19 Pandemic: The Effectiveness of Telehealth
}

\author{
Faisal Muhammad (iD) ${ }^{1, *}$ \\ ${ }^{1}$ Department of Public Health, Faculty of Allied Health Sciences, Daffodil International University, Dhaka, Bangladesh \\ "Corresponding author: Research Associate, Departement of Public Health, Daffodil International University (DIU) 102 \& 102/1 Shukrabad, Mirpur Road Dhanmondi, \\ Dhaka-1207, Bangladesh. Email: fokkanya@yahoo.com \\ Received 2020 July 25; Revised 2020 July 28; Accepted 2020 July 28.
}

Keywords: COVID-19, Pandemic, Telehealth, Global Health

\section{Dear Editor,}

World Health Organization (WHO) has announced coronavirus disease 2019 (COVID-19), a Public Health Emergency of International Concern in January, and a global pandemic in March 2020 (1). The lockdown was imposed almost all over the world for the sake of observing social distancing to prevent the rapid spread of COVID-19 (2). The panic has been created among the healthcare workers (e.g., doctors, nurses) and patients due to the highly contagious nature of the SARS-CoV-2 virus. Many healthcare providers have died of COVID-19. In this pandemic situation, the need for "Telehealth" has become vitally important than ever. The healthcare workers (including doctors) are consumed by fear, and they are now reluctant to render service directly, in which case telehealth could be used to deliver healthcare services when the patients and healthcare providers are separated by distance.. Telehealth uses Information and Communication Technologies (ICT) in exchange for information about the diagnosis, treatment of diseases and injuries, etc. Today, governments across the globe are trying to promote the use of telehealth to improve access to health services (3).

The use of telecommunications has increased in many healthcare institutions during the COVID-19 crisis. Virtual communication continues providing the safest way for the healthcare providers to perform their responsibilities during this crisis, from medical schools to residency programs as well as the patient interactions at home to those in quarantine (4). The main purpose of telemedicine, in general, is to utilize information as well as telecommunication technology to transfer the medical information for diagnosis, treatment, and education. However, the main disadvantages of telemedicine include a failure in the relationship between the patients and the healthcare providers, a failure in the relationship among the healthcare providers, organizational and bureaucratic difficulties, and problems concerning the quality of information. In January 2020 , in some local hospitals located in the Sichuan province of China, the-education to medical staff was provided by an expert group for the rapid response to COVID-19 via portals, consultations networks, and smartphone apps (5).

Although patient care is quite challenging during this pandemic, however, via telehealth, the impact of COVID19 can be reduced on both management of infection and mental health (6). Telehealth can reduce healthcare costs and improve patient outcomes. This type of healthcare delivery can also impede the rapid spread of COVID-19 infection and subdue the pressure on healthcare workers. In the US, tele monitoring has been reported in around 11\% of ICU beds (tele-ICU), which is probably why the US hospitals are not overburdened despite the number of COVID-19 cases and mortality(7). Australia is thought to be one of the most advanced users of telehealth services, and even during this COVID-19 crisis, the allocation has been increased to cover the patient's need remotely (such as using video or telephone). Other countries such as Indonesia, Philippine, and Singapore have followed in the footsteps. Some companies such as Philips have worked with United Nations agencies to use telehealth to deliver healthcare services to less accessible communities in Africa (7). Telehealth makes clinical staff more productive as well as more effective. Telehealth can help healthcare providers manage many patients at one time. In the case of the home management of chronic diseases, after the patients measure their vital signs at home, They will automatically be transmitted to a telehealth nurse (8). Telehealth enables non-COVID-19 patients to continue receiving care without any interruption due to the COVID-19 pandemic. This is peculiarly significant for older people who are most at-risk during this crisis (7).

Currently, there is a huge demand for telehealth across the globe. The clinician's reluctance to adopt telehealth is

Copyright (c) 2020, Middle East Journal of Rehabilitation and Health Studies. This is an open-access article distributed under the terms of the Creative Commons Attribution-NonCommercial 4.0 International License (http://creativecommons.org/licenses/by-nc/4.0/) which permits copy and redistribute the material just in noncommercial usages, provided the original work is properly cited. 
likely to be associated with its limited uptake and lack of funding hold accountable for the slow uptake of telehealth $(3,9,10)$. There are some limitations that bound the use of telehealth. For example, some consultations require physical examinations, which may be difficult to conduct using telehealth (10). The use of telehealth was increased even before the COVID-19 crisis (11). The Centre for Disease Control and Prevention (CDC) projected the global telehealth market increase to about \$30 billion in 2020, which would be higher than the previous \$20.4 billion in 2013 (12). It was predicted that post-pandemic telehealth could help reduce the pressures created by healthcare resource shortages. However, there is a need to look up into the risk and disadvantages of telehealth and make them alleviated. To protect patient data privacy, the governments or concern authorities should ensure IT security. There is also a need for proper training to the telehealth workers across the globe.

\section{Footnotes}

Conflict of Interests: None declared.

Funding/Support: None declared.

\section{References}

1. Sharma S, Bhatta J. Public health challenges during the COVID19 outbreak in Nepal: a commentary. Journal of Health Research. 2020;34(4):373-6. doi:10.1108/jhr-05-2020-0124.

2. Muhammad F. Social Distancing and Lockdown Due to COVID-19 Pandemic Will not Work in Africa. Middle East Journal of Rehabilitation and Health Studies. 2020;7(3). doi:10.5812/mejrh.104271.
3. Bali S. Barriers to Development of Telemedicine in Developing Countries. Telehealth. IntechOpen; 2018. doi: 10.5772/intechopen.81723.

4. Elkbuli A, Ehrlich H, McKenney M. The effective use of telemedicine to save lives and maintain structure in a healthcare system: Current response to COVID-19. The American Journal of Emergency Medicine. 2020. doi:10.1016/j.ajem.2020.04.003.

5. Hong Z, Li N, Li D, Li J, Li B, Xiong W, et al. Telemedicine During the COVID-19 Pandemic: Experiences From Western China. J Med Internet Res. 2020;22(5). e19577. doi: 10.2196/19577. [PubMed: 32349962]. [PubMed Central: PMC7212818].

6. Ojha R, Syed S. Challenges faced by mental health providers and patients during the coronavirus 2019 pandemic due to technological barriers. Internet Interv. 2020;21:100330. doi: 10.1016/j.invent.2020.100330. [PubMed: 32542180]. [PubMed Central: PMC7267786].

7. Sze-Yunn P.Telehealth could be a game changer in the fight against COVID19. Here's why. World Economic Forum; 2020, [cited May 15]. Available from: https://www.weforum.org/agenda/2020/05/telehealth-couldbe-a-game-changer-in-the-fight-against-covid-19-here-s-why/.

8. Radhakrishnan K, Xie B, Jacelon CS. Unsustainable Home Telehealth: A Texas Qualitative Study. Gerontologist. 2016;56(5):830-40. doi: 10.1093/geront/gnv050. [PubMed: 26035878].

9. Bradford NK, Caffery LJ, Smith AC. Awareness, experiences and perceptions of telehealth in a rural Queensland community. BMC Health Serv Res. 2015;15:427. doi: 10.1186/s12913-015-1094-7. [PubMed: 26416464]. [PubMed Central: PMC4587917].

10. Smith AC, Thomas E, Snoswell CL, Haydon H, Mehrotra A, Clemensen J, et al. Telehealth for global emergencies: Implications for coronavirus disease 2019 (COVID-19). J Telemed Telecare. 2020;26(5):309-13. doi: 10.1177/1357633X20916567. [PubMed: 32196391]. [PubMed Central: PMC7140977].

11. Fisk M, Livingstone A, Pit SW. Telehealth in the Context of COVID19: Changing Perspectives in Australia, the United Kingdom, and the United States.J Med Internet Res. 2020;22(6). e19264. doi:10.2196/19264. [PubMed: 32463377]. [PubMed Central: PMC7286230].

12. Russell AW, Silvestri MJ, Fisher GA. The Efficacy and Expansion of Telemedicine to Meet the Growing COVID-19 Pandemic. The National Law Review; 2020, [cited May 15]. Available from: https://www.natlawreview.com/article/efficacy-and-expansiontelemedicine-to-meet-growing-covid-19-pandemic. 